\title{
View Points
}

\section{The Carbon Ranch}

\section{By Courtney White}

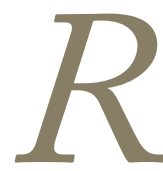

ight now, the only possibility of large-scale removal of greenhouse gases from the atmosphere is through plant photosynthesis and related land-based carbon sequestration activities. Strategies include: enriching soil carbon, no-till farming with perennials, employing climatefriendly livestock practices, conserving natural habitat, restoring degraded watersheds and rangelands, increasing biodiversity, lowering agricultural emissions, and producing local food. Over the past decade, these strategies have been demonstrated individually to be both practical and profitable. A carbon ranch bundles them into an economic and ecological whole for the benefit of all living things.

The purpose of a carbon ranch is to mitigate climate change by sequestering additional $\mathrm{CO}_{2}$ in plants and soils, reducing greenhouse-gas emissions, and producing co-benefits that build ecological and economic resilience in local landscapes.

According to the dictionary, "sequester" means: to withdraw for safekeeping, to place in seclusion, to place into custody, or to hold in solution-all of which are good definitions for the process of sequestering $\mathrm{CO}_{2}$ in plants and soils via photosynthesis and sound stewardship.

The process by which atmospheric $\mathrm{CO}_{2}$ gets converted into soil carbon is neither new nor mysterious. It has been going on for tens of millions of years, and all it requires is sunlight, green plants, water, nutrients, and soil microbes (for more details see the work of Dr Christine Jones at her Web site: www.amazingcarbon.com).

There are four basic steps to the $\mathrm{CO}_{2}$ /soil carbon process: photosynthesis, resynthesis, exudation, and humification.

Photosynthesis: This is the process by which energy in sunlight is transformed into biochemical energy, in the form of a simple sugar called glucose, via green plants-which use $\mathrm{CO}_{2}$ from the air and water from the soil, releasing oxygen as a by-product.

Resynthesis: Through a complex sequence of chemical reactions, glucose is resynthesized into a wide variety of carbon compounds, including carbohydrates (such as cellulose and starch), proteins, organic acids, waxes, and oils (including hydrocarbons) - all of which serve as "fuel" for life on Earth.

Exudation: Around $30-40 \%$ of the carbon created by photosynthesis can be exuded directly into soil to nurture the microbes that grow plants and build healthy soil. This process is essential to the creation of topsoil from the lifeless mineral soil produced by the weathering of rocks over time. The amount of increase in organic carbon is governed by the volume of plant roots per unit of soil and their rate of growth. More active green leaves mean more roots, which mean more carbon exuded.

Humification: Or the creation of humus-a chemically stable type of organic matter composed of large, complex molecules made up of carbon, nitrogen, minerals, and soil particles. Visually, humus is the dark, rich layer of topsoil that people generally associate with stable wetlands, healthy rangelands, and productive farmland. Land management practices that promote the high ecological integrity of the soil are key to the creation and maintenance of humus. Once carbon is sequestered as humus it has a high resistance to decomposition, and therefore can remain intact and stable for hundreds or thousands of years. A lack of humus can mean that the carbon exuded from plant roots simply oxidizes and recycles back to the atmosphere as $\mathrm{CO}_{2}$.

Additionally, high humus content in soil improves water infiltration and storage, due to its sponge-like quality and high water-retaining capacity. Recent research demonstrates that one part humus can retain as much as four parts water. This has important positive consequences for the recharge of aquifers and base flows to rivers and streams.

In sum, the natural process of converting sunlight into humus is an organic way to pull $\mathrm{CO}_{2}$ out of the atmosphere and sequester it in soil for long periods of time. If the land is bare, degraded, or unstable due to erosion and if it can be restored to a healthy condition, with properly functioning carbon, water, mineral, and nutrient cycles, and covered with green plants with deep roots, then the quantity of $\mathrm{CO}_{2}$ that can be sequestered is potentially high. Conversely, when healthy, stable land becomes degraded or loses green plants, the carbon cycle can become disrupted and will release stored $\mathrm{CO}_{2}$ back into the atmosphere.

In other words, healthy soil $=$ healthy carbon cycle $=$ storage of atmospheric $\mathrm{CO}_{2}$. Any land management activity that encourages this equation, especially if it results in the additional storage of $\mathrm{CO}_{2}$, can help fight climate change. Or as Dr Christine Jones puts it: "Any ... practice that improves soil structure is building soil carbon."

What would those practices be? In the rangelands of the Southwestern United States, there are six strategies to 


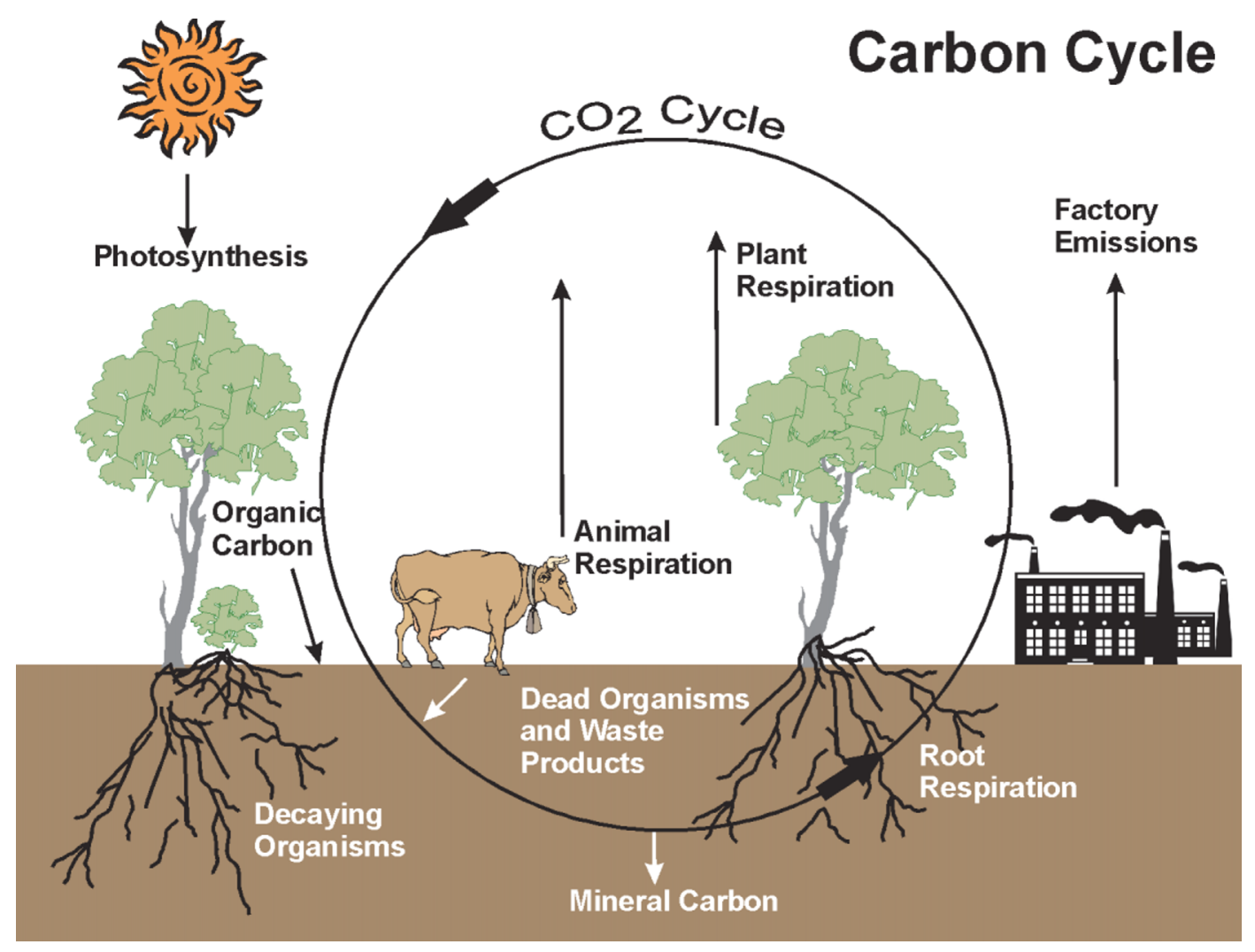

increase or maintain soil health and thus the carbon content of grass- or shrub-dominated ecosystems. Sequestration strategies include: 1) planned grazing systems, especially on degraded soils; 2 ) active restoration of riparian, riverine, and wetland zones; and 3) removal of woody vegetation, where appropriate, so that grass may grow in its stead. Maintenance strategies include: 4) the conservation of open space, so there is no further loss of carbon-storing soils; 5) the implementation of no-till farming practices; and 6) management of land for long-term resilience, i.e., increasing the capacity of land and people to adjust to perturbation and changing climatic conditions.

Fortunately, a great deal of the land management "toolbox" required to implement these strategies has been tried and tested by practitioners, landowners, agencies, and researchers. I will focus on each strategy through the lens of carbon sequestration in soils and briefly review their role in the holistic vision I call a "carbon ranch."

1) Planned grazing systems. The carbon content of soil can be increased by three principal methods: the establishment of green plants on previously bare ground; deepening the roots of existing healthy plants; and the general improvement of nutrient, mineral, and water cycles in a given area. Planned grazing is key to all three. By controlling the timing, intensity, and frequency of animal impact on the land, the "carbon rancher" can improve plant density, diversity, and vigor. Specific actions include: the soil cap-breaking action of herbivore hooves, which promotes seed-to-soil contact and water infiltration; the "herd" effect of concentrated animals, which can provide a positive form of perturbation to a landscape by turning plant litter back into the soil (an intensive version of this effect is sometimes called a "poop-and-stomp"); the stimulative effect of grazing on plants, followed by a long interval of rest (often a year), which causes roots to expand while removing old, oxidized forage; targeted grazing of noxious or invasive plants which promotes native species diversity and vigor; and the targeted application of animal waste, which provides important nutrients to plants and soil microbes.

2) Active restoration of riparian, riverine, and wetland areas. Many arroyos, creeks, rivers, and wetlands in the Southwest exist in a degraded condition-the result of historical overuse by humans, livestock, and industry. The consequence has been widespread soil erosion, loss of riparian vegetation, the disruption of hydrological cycles, the decline of water storage capacity in stream banks, the loss of wetlands, and many other examples of land "sickness." The restoration of these areas to health, especially efforts that contribute to soil retention and formation, such as the reestablishment of humus-rich wetlands, will result in additional storage of atmospheric $\mathrm{CO}_{2}$ in soils. The "toolbox" for the restoration of these areas is now well-developed, practical, and could be implemented at scale if desired. There are many co-benefits of restoring riparian areas and wetlands to health as well, including: improved habitat for wildlife, increased forage for herbivores, improved water 


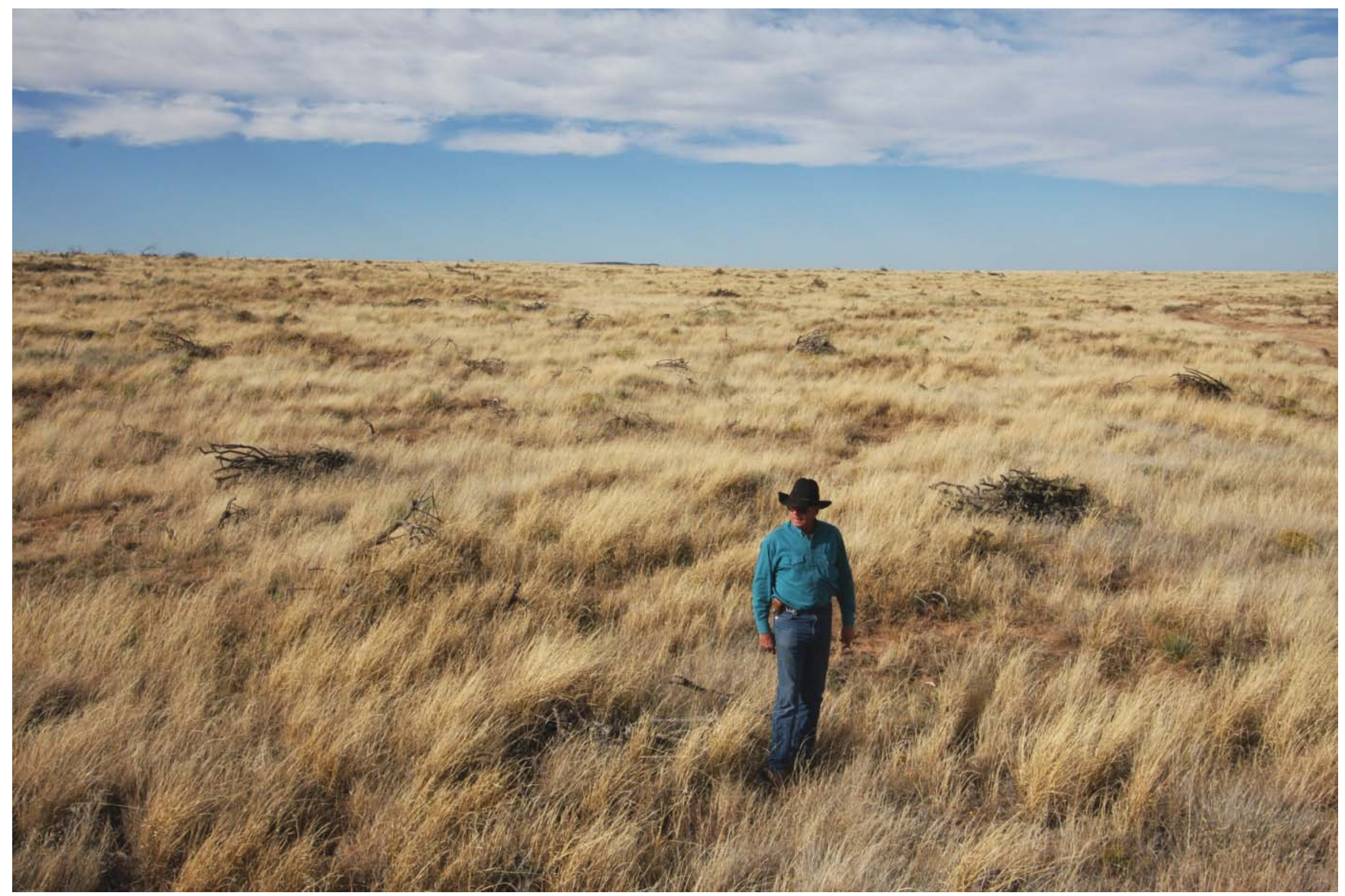

Rancher Tom Sidwell and grasslands he restored on the JX Ranch, near Tucumcari, NM. Photo by Courtney White.

quality and quantity for downstream users, and a reduction in erosion and sediment transport.

3) Removal of woody vegetation. Many meadows, valleys, and rangelands have witnessed a dramatic invasion of woody species, such as pinon and juniper trees, over the past century, mostly as a consequence of the suppression of natural fire and overgrazing by livestock (which removes the grass needed to carry a fire). The elimination of over-abundant trees by agencies and landowners, via prescribed fire or other means, has been the focus of much restoration activity in the Southwest recently. The general goal of this work is to encourage grass species to grow in place of trees, thus improving the carbon-storing capacity of the soil. Not only can soils store more $\mathrm{CO}_{2}$ than trees, they also have the advantage of relative permanence. Trees can burn up, be cut down, or die of disease or old age, all of which can ultimately release stored $\mathrm{CO}_{2}$ back into the atmosphere. Additionally, the removal of trees has an important co-benefit: they are a potential source of local biomass energy production, which can help reduce a ranch's carbon footprint.

Maintenance strategies that help keep stored $\mathrm{CO}_{2}$ in soils include:

4) The conservation of open space. The loss of forest, range, or agricultural land to subdivision or other types of development can dramatically reduce or eliminate the land's ability to pull
$\mathrm{CO}_{2}$ out of the atmosphere via green plants. Fortunately, there are multiple strategies that conserve open space, including public parks, private purchase, conservation easements, tax incentives, zoning, and economic diversification that helps to keep a farm or ranch in operation. Perhaps most importantly, the protection of the planet's forests and peatlands from destruction is crucial to an overall climate change mitigation effort. Not only are forests and peatlands important sinks for $\mathrm{CO}_{2}$, their destruction releases large amounts of stored carbon back into the atmosphere.

5) The implementation of no-till farming practices. Plowing exposes stored soil carbon to the elements, including the erosive power of wind and rain, which can quickly cause it to dissipate back into the atmosphere as $\mathrm{CO}_{2}$. No-till farming practices, especially organic ones (no pesticides or herbicides), not only protect soil carbon and reduce erosion, they often improve soil structure by promoting the creation of humus. Additionally, farming practices that leave plants in the ground year-round both protect stored soil carbon and promote increased storage via photosynthesis. An important co-benefit of organic no-till practices is the production of healthy food.

6) Building long-term resilience. Nature, like society, does not stand still for long. Things change constantly, sometimes slowly, sometimes in a rush. Some changes are significant, 
such as a major forest fire or a prolonged drought, and can result in ecological threshold-crossing events, often with deleterious consequences. "Resilience" refers to the capacity of land, or people, to "bend" with these changes without "breaking." Managing a forest through thinning and prescribed fire so that it can avoid a destructive, catastrophic fire is an example of building resilience into a system. Managing land for long-term carbon sequestration in vegetation and soils requires building resilience as well, including the economic resilience of the landowners, managers, and community members.

All of these strategies have been demonstrated to be effective in a wide variety of landscapes. The difficult job now is how to integrate them into a "climate-friendly" landscape that sequesters increasing amounts of $\mathrm{CO}_{2}$ each year, and does so economically.

\section{The Sins of Emission}

\section{Let's be clear... We will still have to radically reduce carbon emissions, and do so quickly. We will still have to elimi- nate the use of fossil fuels and adopt substantially more sustainable agricultural methods. We will still have to deal with the effects of ecosystems damaged by carbon overload. - editors of The Wall Street Journal}

Reality check: the increased sequestration of $\mathrm{CO}_{2}$ in soils will not solve climate change. It will not even be close if the emissions of greenhouse gases are not dramatically reduced at the same time. According to experts, this reduction must be on the order of $50-80 \%$ of current emissions levels within 50 years. Accomplishing this goal will require a massive rearrangement of our energy sector toward fossil low-carbon technologies as well as big changes in the everyday lives of Americans.

A carbon ranch can help in three ways: 1) by measuring and then reducing the amount of greenhouse gas emissions it contributes to the atmosphere; 2) by producing renewable energy "on-ranch" which it can use itself and/or sell to a local or regional power grid; and 3) by participating in local food and restoration activities that lower our economy's dependence on fossil fuels.

A carbon ranch can also help by confronting the controversy over "offsets" and carbon "credits"- the two strategies most frequently touted by governments, businesses, agencies, and others for encouraging the creation of a so-called "carbon marketplace." In this marketplace, "credits" created by the sequestration of $\mathrm{CO}_{2}$ in one place can be "sold" or traded to "offset" a $\mathrm{CO}_{2}$-polluting entity, such as a coal plant or airline company, someplace else, supposedly to the benefit of all. In reality, these schemes appear to mostly offset our guilty feelings rather than actually affect climate change.

Here are these ideas in more detail:

1) Reducing the "footprint" of a carbon ranch. This is a two-step process: Assess the amount of greenhouse gas emissions that are rising from a particular landscape or operation; and second, follow this assessment with a concerted effort to reduce these emissions. One way to measure this carbon footprint is to conduct a Life-Cycle Assessment (LCA) of an enterprise- which is an inventory of the material and energy inputs and outputs characteristic of each stage of a product's life cycle. This is a well-recognized procedure for tracking the ecological impacts of, say, a television set or a refrigerator, and different types of LCAs exist for different types of products.

For a carbon ranch, there are four important measures of its LCA: cumulative energy use, ecological footprint, greenhouse-gas emissions, and eutrophying emissions.

The first three measurements are relatively straightforward and there are many credible methodologies today to calculate energy use, ecological footprints, and emissions, although most are designed for urban contexts or industrial agriculture. However, the fourth measurement-eutrophying emissions-has been the source of considerable controversy in recent years. It refers to the amount of methane produced by the digestive system of livestock during its time on the ranch, farm, or feedlot-and in the public's mind the connotation is negative. That is because the public has conflated a natural biological process-belching cows-with fossil fuel-intensive industrial livestock production activities, including chemical fertilizer production, deforestation for pasture, cultivation of feed crops (corn), and the transportation of feed and animal products. As a result, there is an impression among the public at large that one answer to the climate crisis is to "eat less red meat"-an opinion that I have heard repeatedly at conferences and meetings.

\section{Personally, I think an answer is to eat more meat-from a carbon ranch.}

For the purposes of a carbon ranch, the methane emission issue is just one part of the overall "footprint" assessment. The goal of an LCA is to measure an operation's energy use and emissions so that it can reduce both over time. Ultimately, the goal is to become carbon-neutral or, ideally, carbon-negative-meaning, the amount of $\mathrm{CO}_{2}$ sequestered is greater than the ranch's carbon footprint.

2) Producing renewable energy. Anything that a carbon ranch can do to produce energy on-site will help balance its energy "footprint" and could reduce the economy's overall dependence on fossil fuels. This includes wind and solar farms, the production of biodiesel from certain on-site crops for use in ranch vehicles, biomass for cogeneration projects (this is especially attractive if it uses the woody debris being removed from the ranch anyway), micro-hydro, micro-wind, and solar for domestic use, and perhaps other as yet unrealized renewable energy alternatives.

3) Participating in a local economy. A carbon ranch should carefully consider its role in the "footprint" of the greater economy. Are its products traveling long distances or otherwise burning large amounts of fossil fuels? Ditto for visitors, ranch owners, and employees. Does participating in a local economy—food, recreation, and energy —increase or decrease 


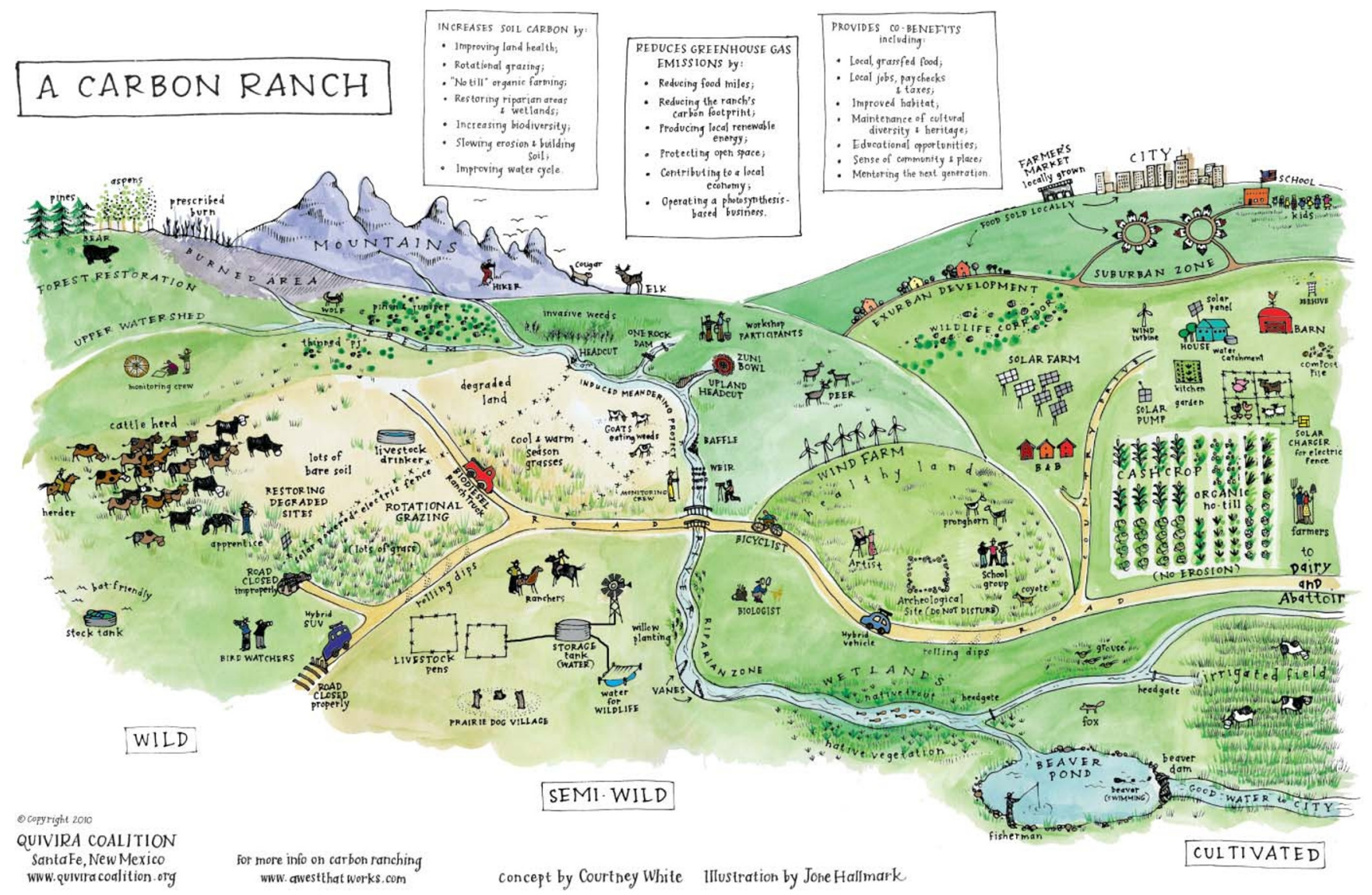

the overall "footprint" of the ranch? How else can it reduce greenhouse-gas emissions locally or regionally? For example, it is generally accepted that involvement in a local food market, where the distances between producer and eater are short, shrinks the fossil "footprint" of a ranch considerably. There is some contradictory research on this point, however. In my opinion, the technical issues of local vs. global food systems in terms of food miles traveled is largely neutralized by the wide variety of co-benefits that local food brings economically and ecologically.

4) The trouble with offsets. Many observers-myself included-have become increasingly skeptical of the offset concept at regional or national scales. Objections include:

- We need actual net reductions of atmospheric $\mathrm{CO}_{2}$ not just the neutralizing "offset" of a polluter by a sequesterer. And we need these net reductions soon.

- It is not acceptable to let a big, industrial polluter "off the hook" with an offset.

- It is unrealistic to expect the same system that created the climate problem in the first place-i.e., our current economy and specifically its financial sector-to solve this problem and to do so with the same financial tools.

- At best, offsets may be illusory; at worst they're fraudulentthus imperiling the whole purpose of the idea.

- The monitoring required to quantitatively verify actual and additional (meaning a net increase in) $\mathrm{CO}_{2}$ sequestration in the soil in order to satisfy the marketplace is too complicated, expensive, and intrusive for many landowners. Out West, many ranchers already feel like there are too many "people-with-clipboards" walking across the land. And if protocols are not considered "user friendly" by landowners, then skepticism will remain high in a community that already has doubts about climate change.

While offsets and carbon credits may not be the economic engine of the future, they highlight an important challenge for carbon ranching: profitability. If not offsets then how can a landowner who desires to mitigate climate change earn a paycheck, without which there will be no carbon ranching?

One idea is to include "climate-friendly" practices as an added value to the marketing of ranch products, such as its beef. Another is to create a "carbon market" at the local level. A county government, for example, could help to create a local carbon market to help offset its judicial buildings or schools or prisons. It could possibly do so through its ability to tax, zone, and otherwise regulate at the county level. It would still have to deal with some of the other challenges confronting offsets, but at least it would keep the marketplace local.

Another idea might be to reward landowners financially for meeting sequestration and emissions goals. The federal government routinely subsidizes rural economic development enterprises that the private marketplace will not touch, such 


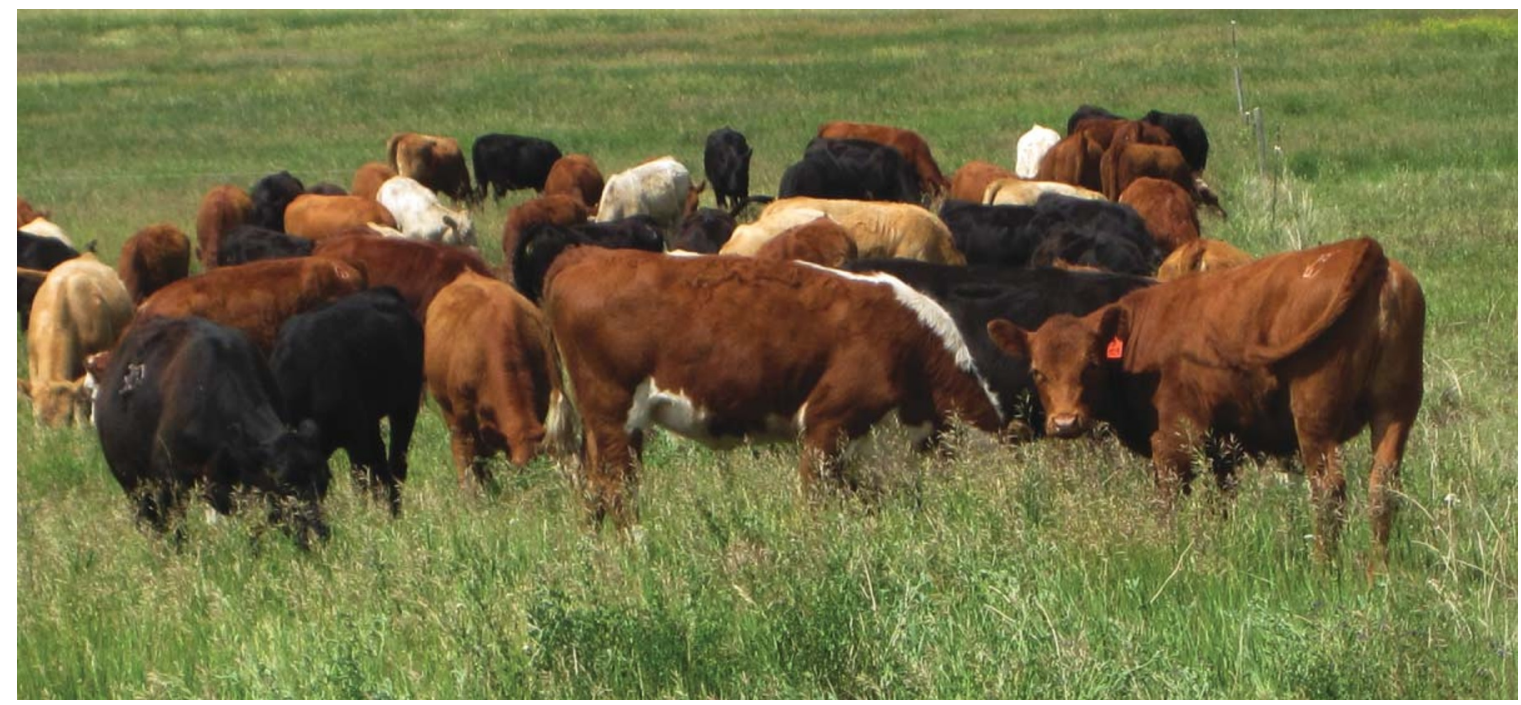

Grassfed cattle. Photo by Tamara Gadzia.

as the current effort to bring high-speed broadband Internet to rural communities. Additionally, the government often provides incentives to businesses for market-based approaches, including corn-based ethanol production, solar power development, and wind technology (and do not forget the federal government's catalyzing role in the birth of the Internet). It would be perfectly logical, therefore, to reward early adopters of carbon ranching with a direct financial payment as a means to stir up new markets.

\section{The Joy of Co-Benefits}

"Carbon ranching has no downside." - John Wick, rancher and director of the Marin Carbon Project

In its effort to sequester carbon in soil and reduce emissions, a carbon ranch also produces co-benefits that make the whole enterprise even more vital. They include:

- Local grass-fed and organic food. By managing land for a healthy grass cover, a carbon ranch is the natural setting for raising grass-fed livestock, whose environmental and human-health benefits are well documented. Additionally, the market for organic, grass-fed meat is growing steadily, which means this could be a way to monetize "climate-friendly" beef as an economic strategy.

- Improved ecosystem services. In 2005, the United Nations published its Millennium Ecosystem Assessment, a global evaluation of ecosystem services on which human wellbeing depend. These services include the provision of food, fresh water, wood, fiber, fuel, and biodiversity; flood, pest, and disease regulation; nutrient cycling, soil stability, biotic integrity, watershed function, and photosynthesis; and spiritual, educational, recreational, and aesthetic experiences. According to the Assessment, nearly all of these services are in gradual or steep decline. By improving soil structure and grass cover via grazing management, riparian and wetland restoration, tree thinning, open-space protection, and no-till farming practices, a carbon ranch can contribute substantially to reversing the decline in these essential services.

- Habitat protection. In addition to the protection of the open space necessary for wildlife, a carbon ranch promotes the peaceful coexistence of domestic and wild animal populations. That is because it operates on the principle that the natural processes that sustain wildlife habitat, biological diversity, and functioning watersheds are the same processes that make land productive for livestock. Healthy land, in other words, is the basis for healthy relationships between all living things.

- Rural economic development. Producing local food, restoring creeks and rangelands, marketing "climate-friendly" enterprises, and developing local energy will require a great deal of work, and therefore could create, potentially, a great deal of paychecks for rural residents. The number of eroded creeks and wetlands in the Southwest that could be restored, for example, is huge, which means the potential for employing people in restoration jobs is equally huge.

- Maintenance of culture and diversity. Since a carbon ranch involves livestock, horses, roping, branding, as well as farming, irrigating, timber harvesting, wildlife viewing, and many other traditional activities, it can strengthen and support local and regional land-based cultures. It will require a mixing of innovation with tradition, but this can be a healthy way of rejuvenating a sense of community and cultural continuity.

- Educational opportunities. A carbon ranch requires a careful blending of ecology, economics, stewardship, restoration activities, monitoring, collaboration, and innovation, which means it has the potential to become a dynamic site for a wide variety of educational opportunities, including tours, workshops, field trips, outdoor classrooms, clinics, and training programs. 
- Bridging the urban-rural divide. Many people concerned about climate change live in cities or other urban arrangements while most carbon sequestration work will take place in the countryside, which means a carbon ranch has a huge potential to bridge the long-standing and expanding gulf that separates urban and rural residents today. In other words, the urban can support rural economically, politically, and socially, while rural delivers the climate-change mitigation that we all need so urgently.

- Participation in a local economy. Much has been written in recent years about the value of local economies. A carbon ranch can help by its emphasis on local food production, energy development, and localized restoration activities.

- Opportunities for the next generation. If a carbon ranch could become a profitable enterprise, then it would undoubtedly become attractive to young people who want to get into (or back to) farming and ranching or otherwise pitch in with the effort to fight climate change. Additionally, older farmers and ranchers could be enlisted to help mentor the next generation of land managers, especially if they have expertise in one or more of the necessary skills to run a carbon ranch.

There are other important co-benefits that carbon ranching can provide, including reconnecting urban residents with a source of their food; softening the effects of drought on landowners; and assisting with the terribly important challenge of feeding a global population that is expected to reach nine billion people by mid-century.

None of this will be easy. In fact, the obstacles standing in the way of implementing a carbon ranch and sharing its many co-benefits are large and diverse. Is it worth trying anyway? Absolutely. If a carbon ranch could make a difference in the fight against climate change-which I consider the overarching crisis of the 21st century-then we must try. The alternative- not trying-means we consign our future to politics, technology, and wishful thinking, none of which have made a difference so far.

Some see salvation in high technology, including the "capture" of $\mathrm{CO}_{2}$ at its source, to be stored underground, or the "scrubbing" of greenhouse gases from the atmosphere by hundreds of thousands of boxcar-sized filtering machines. Unfortunately, these technologies, even if practical, are years away from deployment. And the climate crisis, as evidenced by recent headlines, is happening now.

Which leads to a question: what about low technology? Carbon ranching does not need to be invented. It already exists. We know how to grow grass with animals. We have learned how to fix creeks and heal wetlands. We are getting good at producing local grass-fed food. We will figure out how to reduce our carbon footprint, and develop local renewable energy sources profitably. We do not need high technology - we have the miracle of photosynthesis already. Too often, our eyes seem fixed on the stars and our minds dazzled by distant horizons, blinding us to possibilities closer to home. Perhaps we should be looking down, not up.

At the grass and the roots.

Author is Executive Director of the Quivira Coalition, 1413 Second Street, Suite 1, Santa Fe, NM 87505, USA, executive@ quiviracoalition.org. This essay is an abridged version of "The Carbon Ranch: Fighting Climate Change... One Acre at a Time," which originally appeared in the Quivira Coalition publication Resilience in December 2010. For the complete original essay, including additional sources of information, see http://www.awestthatworks.com/2Essays/CarbonRanch/ CourtneyWhiteACarbonRanch.pdf. 